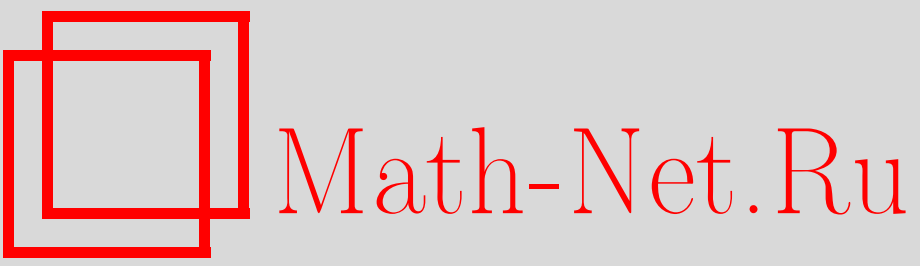

О. И. Алтухов, В. В. Фрыгин, Термодинамический расчёт температуры и состава продуктов горения пиротехнических и газогенерирующих зарядов для наддува порошковых огнетушителей, Вестн. Сам. гос. техн. ун-та. Сер. Физ.-мат. науки, 2011, выпуск 3(), 143-148

DOI: https://doi.org/10.14498/vsgtu968

Использование Общероссийского математического портала Math-Net.Ru подразумевает, что вы прочитали и согласны с пользовательским соглашением

http://www.mathnet.ru/rus/agreement

Параметры загрузки:

IP : 54.209 .52 .79

26 апреля 2023 г., 16:41:26 
УДК 536.46:614.845.1

\title{
ТЕРМОДИНАМИЧЕСКИЙ РАСЧЁТ ТЕМПЕРАТУРЫ И СОСТАВА ПРОДУКТОВ ГОРЕНИЯ ПИРОТЕХНИЧЕСКИХ И ГАЗОГЕНЕРИРУЮЩИХ ЗАРЯДОВ ДЛЯ НАДДУВА ПОРОШКОВЫХ ОГНЕТУШИТЕЛЕЙ
}

\section{О. И. Алтухов ${ }^{1}$, В. В. Фрыгин ${ }^{2}$}

1 Самарский государственный технический университет,

443100, Самара, ул. Молодогвардейская, 244.

2 СЭУ ФПС «Испытательная пожарная лаборатория» по Самарской области 443096, г. Самара, ул. Пролетарская, 74.

E-mails: oleg.altuhov@bk.ru, wffiere@rambler.ru

\begin{abstract}
Представлены основные результаты термодинамических расчётов реакиии горения пиротехнических газогенерирующих зарлдов для наддува порошковых огнетушителей. На основании расчётов определены адиабатическая температура горения и состав продуктов горения газогенерирующих зарядов. Определены исходные химические соединения для разработки газогенерирующего заряда с низкой температурой генерируемых газов.
\end{abstract}

Ключевые слова: пиротехнический газогенерирующий заряд, горение, температура, продукты горения.

Введение. Реализация в пожарной технике процессов генерирования газов путём сжигания химических составов нашла своё применение в порошковых огнетушителях, в которых образующийся газ используется в качестве исходных компонентов для выброса огнетушащего вещества. В соответствии с $[1,2]$ температура корпуса газогенерирующего устройства и струи газа не должна приводить к спеканию огнетушащего вещества. Поэтому основной задачей при разработке новых пиротехнических составов является снижение температуры генерируемых газов.

В настоящее время существует большое количество химических соединений, как органических, так и неорганических, которые используются для создания пиротехнических зарядов [3,4]. На основании свойств этих компонентов бывает трудно определить - подходит ли какое-то конкретное вещество для использования его в качестве окислителя, горючего, связующего, флегматизатора, охлаждающей или газифицирующей добавки для создания нового пиротехнического состава. Да и на практике проверить сочетания выбранных компонентов, сжигая их в различных соотношениях, представляется процессом очень трудоёмким. Поэтому необходим термодинамический расчёт пиросоставов с использованием программного обеспечения для подбора компонентов состава.

В настоящей работе проведены термодинамические расчёты адиабатической температуры горения и состава газообразных продуктов горения пиротехнических газогенерирующих зарядов для наддува порошковых огнетушителей. Работа является продолжением экспериментальных исследований

Олег Игоревич Алтухов, младший научный сотрудник, инженерный центр «Самораспространяющийся высокотемпературный синтез». Валерий Валентинович Фрыгин, начальник лаборатории. 
[5-7] авторов по отработке пиротехнических зарядов с низкой температурой генерируемых газов.

1. Материалы и методы. Первая серия термодинамических расчётов проведена для базовой смеси «окислитель + горючее» для различных значений соотношения компонентов.

Выбор исходных компонентов состава осуществлялся исходя из общих требований, предъявляемых к газообразующим составам, а также специальных требований к газогенераторам, предназначенным для наддува порошковых огнетушителей [1-3].

В результате обзора литературы установлено, что оптимальным является использование окислителей второго и третьего типов разложения [4]. Окислители первого топохимического типа разложения использовать нецелесообразно, так как реакция горения в этом случае протекает неустойчиво, а сами окислители (например, $\mathrm{MnO}_{2}, \mathrm{KMnO}_{4}$ ) имеют низкий процент содержания свободного кислорода. Для исследований был выбран нитрат калия (HK), который сначала плавится, затем разлагается, а между температурой плавления и разложения имеется достаточный интервал [4].

В качестве горючего и одновременно связующего был выбран бакелит $(\mathrm{БK})$, являющийся реактопластом и реагирующий с окислителем с образованием прочных шлаков, препятствующих уносу жидких продуктов реакции из зоны горения.

Вторая серия расчётов проведена для тройных смесей «окислитель + горючее + газифицирующая добавка» для различных значений соотношения компонентов. В качестве газифицирующей добавки (ГД) поочередно были исследованы смеси с содержанием циануровой кислоты (ЦК), аммелида (АМ), меламина (МА) и дициандиамида (ДЦДА). Их доля в тройной смеси составляла $10 \%, 15 \%, 20 \%, 25 \%$ и $30 \%$ массы для каждого компонента.

Расчёты проведены с использованием программы Thermo, разработанной в Институте структурной макрокинетики и проблем материаловедения РАН, для исследования термодинамического равновесия в сложных многоэлементных гетерофазных системах и использования в задачах анализа возможного состава продуктов синтеза (конденсированных и газообразных) и адиабатической температуры горения системы [8]. При осуществлении термодинамических расчётов предполагалось, что процесс является адиабатическим, т. е. отсутствуют тепловые потери из зоны реакции. Расчёт характеристик равновесия осуществляется на основе минимизации термодинамического потенциала системы, выражение для которого учитывает вклады термодинамических потенциалов всех соединений, содержащихся в системе, и их концентрации. Алгоритм минимизации термодинамического потенциала основан на методе градиентного спуска. Расчёты произведены с использованием энтальпий образования веществ, значения которых приняты в соответствии с $[9,10]$ : 494 кДж/моль для НК; 300 кДж/моль для БК; 690,8 кДж/моль для ЦК; 64,3 кДж/моль для МА; 492,9 кДж/моль для АМ; 24,9 кДж/моль для ДЦДА.

2. Результаты термодинамического исследования горения двойной смеси HK-БK. Результаты расчёта адиабатической температуры горения $T_{a d}$ двойной смеси НК-БК приведены на рис. 1. 
Из графика видно, что адиабатическая температура горения $T_{a d}$ двойной смеси НК-БК уменьшается с 1521 до 1162 K с увеличением содержания БК.

Результаты расчёта состава газообразных продуктов горения двойной смеси НK-БК сведены в табл. 1.

Из таблицы видно, что основу продуктов горения двойной смеси НK-БК составляют оксид углерода и водород. Также в заметных количествах образуются азот, метан, диоксид углерода и пары воды, причём доля последних повышается с увеличением содержания БК.

3. Результаты термодинамического исследования горения тройных смесей HK-БК-ГД. В качестве основы тройной смеси была выбрана двойная смесь НК-БК в отношении $7 / 3$, так как именно эта смесь обладает самой высокой скоростью горения из исследованных бинарных смесей [6].

Результаты расчёта адиабатической температуры горения $T_{a d}$ тройных смесей НК-БК-ЦК и НК-БК-МА приведены на рис. 2, а для НК-БК-АМ и HК-БК-ДЦЦА - на рис. 3. Из графиков зависимости $T_{a d}$ от содержания ГД в тройных смесях видно, что самая низкая температура наблюдается в тройной смеси с содержанием ЦК $(1170 \div 1370 \mathrm{~K})$; причём снижение температуры наблюдается с увеличением содержания ЦК в тройной смеси.

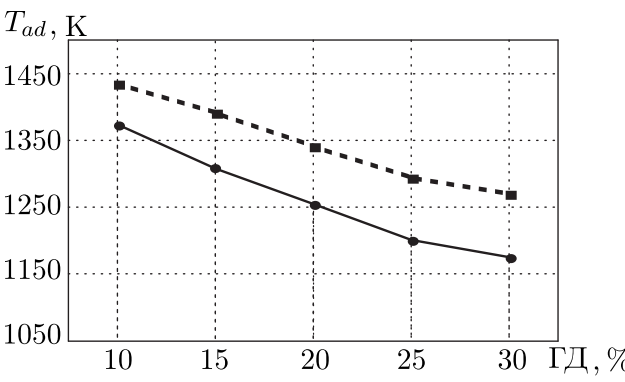

Рис. 2. Зависимость $T_{a d}$ от содержания ЦК в смеси НК-БК-ЦК (штриховая линия) и МА в смеси НК-БК-МА (сплошная линия)

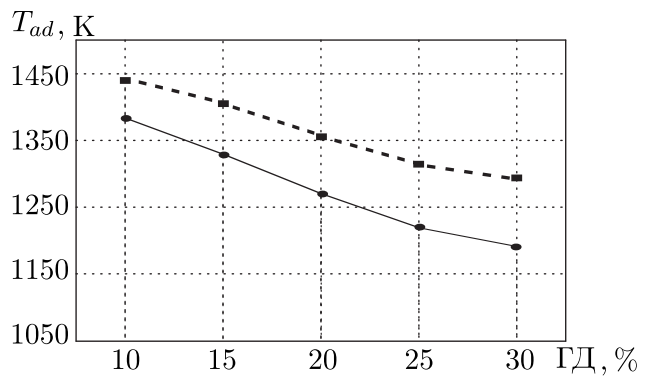

Рис. 3. Зависимость $T_{a d}$ от содержания АМ в смеси НК-БК-АМ (штриховая линия) и ДЦДА в смеси НК-БК-ДЦДА (сплошная линия)

Результаты расчёта состава продуктов горения тройных смесей сведены в табл. 2. Как видно из табл. 2, основу газообразных продуктов горения тройных смесей с ГД составляют оксид углерода, водород и азот, причём увеличение содержание последнего, как и предполагалось, произошло из-за использования в качестве ГД азотсодержащих соединений, таких как КЦ, MA, AM и ДЦДА. Как и при сжигании двойной смеси НК-БК, в заметных количествах образуются азот, метан, диоксид углерода и пары воды. По количественному содержанию «желаемого» безвредного газа - диоксида углерода на фоне исследуемых ГД перспективнее всех выглядит ЦК (1,74-9,29\%). 
Таблица 1

Результаты расчёта состава газообразных продуктов горения двойной смеси НК-БК

\begin{tabular}{c|c|c|c|c|c|c}
\hline $\begin{array}{c}\text { Содер- } \\
\text { жание } \\
\text { БК, \% }\end{array}$ & Метан & $\begin{array}{c}\text { Оксид } \\
\text { углерода }\end{array}$ & $\begin{array}{c}\text { Диоксид } \\
\text { углерода }\end{array}$ & Водород & Азот & Пары воды \\
\hline 30 & 0,58 & 53 & 0,5 & 31,7 & 13,4 & 0,82 \\
40 & 2,15 & 45,13 & 1,26 & 38 & 11,2 & 2,26 \\
50 & 4,33 & 37,87 & 2,57 & 41,15 & 9,27 & 4,81 \\
60 & 7,44 & 30,14 & 3,99 & 42,92 & 7,39 & 8,12 \\
70 & 11 & 23,6 & 4,87 & 43,83 & 5,5 & 11,2 \\
\hline
\end{tabular}

Таблица 2

Результаты расчёта состава газообразных продуктов горения тройных смесей

\begin{tabular}{|c|c|c|c|c|c|c|}
\hline \multirow{2}{*}{$\begin{array}{c}\text { Содер- } \\
\text { жание } \\
\text { ГД, \% }\end{array}$} & \multicolumn{6}{|c|}{ Продукты горения, \% } \\
\hline & Метан & $\begin{array}{c}\text { Оксид } \\
\text { углерода }\end{array}$ & $\begin{array}{l}\text { Диоксид } \\
\text { углерода } \\
\end{array}$ & Водород & Азот & Пары воды \\
\hline \multicolumn{7}{|c|}{ НК-БК-ЦК } \\
\hline 10 & 1,38 & 49,34 & 1,74 & 29,39 & 16,02 & 2,13 \\
\hline 15 & 1,73 & 46,79 & 3,11 & 27,54 & 17,52 & 3,31 \\
\hline 20 & 2,14 & 43,18 & 4,91 & 26,28 & 18,77 & 4,72 \\
\hline 25 & 2,59 & 38,29 & 7,51 & 24,41 & 20,61 & 6,59 \\
\hline 30 & 2,69 & 35,55 & 9,29 & 22,75 & 22,11 & 7,61 \\
\hline \multicolumn{7}{|c|}{ HK-БK-MA } \\
\hline 10 & 1,39 & 42,53 & 0,73 & 33,77 & 20,22 & 1,36 \\
\hline 15 & 1,88 & 37,91 & 0,91 & 34,11 & 23,45 & 1,74 \\
\hline 20 & 2,41 & 33,25 & 1,19 & 34,44 & 26,34 & 2,37 \\
\hline 25 & 3,13 & 28,43 & 1,46 & 34,37 & 29,49 & 3,06 \\
\hline 30 & 3,61 & 25,35 & 1,56 & 33,75 & 32,29 & 3,44 \\
\hline \multicolumn{7}{|c|}{ HK-БK-AM } \\
\hline 10 & 1,45 & 46,82 & 1,43 & 30,68 & 17,56 & 1,97 \\
\hline 15 & 1,78 & 44,12 & 2,21 & 29,62 & 19,48 & 2,79 \\
\hline 20 & 2,36 & 39,89 & 3,52 & 28,61 & 21,46 & 4,16 \\
\hline 25 & 2,91 & 35,27 & 5,08 & 27,32 & 23,71 & 5,71 \\
\hline 30 & 3,19 & 32,19 & 6,24 & 25,81 & 25,84 & 6,72 \\
\hline \multicolumn{7}{|c|}{ НК-БК-ДШДА } \\
\hline 10 & 1,35 & 42,43 & 0,69 & 33,83 & 20,41 & 1,29 \\
\hline 15 & 1,69 & 38,13 & 0,81 & 34,31 & 23,47 & 1,59 \\
\hline 20 & 2,27 & 33,55 & 1,02 & 34,75 & 26,29 & 2,12 \\
\hline 25 & 2,88 & 29,23 & 1,23 & 34,84 & 29,17 & 2,65 \\
\hline 30 & 3,29 & 26,15 & 1,31 & 34,38 & 31,91 & 2,96 \\
\hline
\end{tabular}


4. Обсуждение результатов и выводы. Определение температуры горения пиротехнических составов имеет большое значение, так как является критерием для оценки существующих и облегчает создание новых, более совершенных составов.

Анализ полученных результатов адиабатической температуры горения $T_{a d}$ исследованных тройных смесей позволяет сделать вывод о практической целесообразности применения в качестве газифицирующей добавки ЦК, так как такие составы обладают самой низкой температурой горения. Низкая температура горения пиротехнического заряда необходима для разработки газогенерирующего устройства с низкой температурой генерируемых газов, которая не будет приводить к спеканию огнетушащего вещества в порошковом огнетушителе.

Приведённые данные дают представление о составе продуктов газификации газогенерирующего заряда. Так как масса генерируемых газов не превышает 1\% от массы выбрасываемого ими порошка, применение газогенерирующих устройств на основе приведённых выше компонентов для наддува порошковых огнетушителей опасности не представляет из-за малой концентрации газообразных продуктов в воздухе.

Полученные авторами результаты расчёта адиабатической температуры и состава газообразных продуктов горения подтверждаются проведёнными в работе [11] экспериментальными исследованиями (при $T_{a d}$ порядка $1120 \div$ $1360 \mathrm{~K}$ получен следующий состав продуктов газификации: оксид углерода (57\%), диоксид углерода $(5,3 \%)$, азот $(29,4 \%)$, метан $(3,7 \%)$, водород $(4,3 \%)$, пары воды $(0,3 \%))$. Основу газогенерирующего заряда в работе [11] составляют НK и БК, в качестве добавок используются аммофос, карбонат магния основной и хлорид калия.

\section{БИБЛИОГРАФИЧЕСКИЙ СПИСОК}

1. Собуръ C. В. Огнетушители: Справочник. М.: Пожкнига, 2004. 96 с. [Sobur' S. V. Fire extinguishers: Handbook. Moscow: Pozhkniga, 2004. 96 pp.]

2. Исавнин Н. В. Средства порошкового пожаротушения. М.: Стройиздат, 1983. 156 с. [Isavnin N. V. Means of Powder Fire Fighting. Moscow: Stroyizdat, 1983. 156 pp.]

3. Шидловский А.А. Основы пиротехники. М.: Машиностроение, 1973.320 с. [Shidlovskiy A. A. Fundamentals of pyrotechnics. Moscow: Mashinostroenie, 1973. 320 pp.]

4. Силин Н.А., Ващенко В.А., Зарипов Н.И., Кашпоров Л.Я., Шахиджсанов Е.С., Шейнман Л.Е. Окислители гетерогенных конденсированных систем. М.: Машиностроение, 1978. 456 с. [Silin N.A., Vashchenko V.A., Zaripov N.I., Kashporov L. Ya., Shahidzhanov E.S., Scheinman L.E. Oxidants of heterogeneous condensed systems. Moscow: Mashinostroenie, 1978. 456 pp.]

5. Алтухов О.И. Порошковые огнетушители с газогенерирующими устройствами, с сокращенным временем работы и низкой температурой газа/ В сб.: Будущее технической науки: Тез. докл. VII Международн. молодёжн. научн.-техн. конф-ции. Н. Новгород, 2008. С. 345-346. [Altuhov O.I. Powder-type fire extinguishers with gasgenerating devices, with reduced operating time and low temperature gas / In: Budushchee tekhnicheskoiy nauki. N. Novgorod, 2008. Pp. 345-346].

6. Алтухов О.И. Источники холодного газа для порошковых огнетушителей / В сб.: XVI Туполевские чтения: Тр. Международн. молодёжн. научн. конф-ции. Т. 1. Казань, 2008. C. 299-300. [Altuhov O. I. Cold gas sources for powder-type fire extinguishing / In: XVI Tupolev's reading. Vol.1. Kazan', 2008. Pp. 299-300]. 
7. Алтухов О.И., Амосов А.П., Каплун Е.С., Самборук А.Р., Фрыгин В. В. О порошковом огнетушителе с источником холодного газа и сокращенным временем работы / В сб.: Системы безопасности (СБ-2009): Материалы 18-ой научн.-техн. конф-ции. М.: Академия ГПС МЧС России, 2009. 232-233 c. [Altuhov O. I., Amosov A. P., Kaplun E. S., Samboruk A.R., Frygin V. V. On a powder-type fire extinguisher with cold gas source and short-time working/ In: Safety Systems. Moscow: Akademiya GPS MCHS Rossii, 2009. 232-233 pp.]

8. Амосов А.П., Боровинская И. П., Мержанов А.Г. Порошковая технология самораспространяющегося высокотемпературного синтеза материалов. М.: Машиностроение-1, 2007. 568 c. [Amosov A. P., Borovinskaya I. P., Merzhanov A. G. Powder Technology of SelfPropagating High-Temperature Synthesis of Materials. Moscow: Mashinostroenie-1, 2007. 568 pp.]

9. Карапетъляи, M. X, Карапетьяни, М. Л. Основные термодинамические константы неорганических и органических веществ. М.: Химия, 1968. 464 с.; англ. пер.: Karapet'yants M. Kh., Karapet'yants M.L. Thermodynamic Constants of Inorganic and Organic Compounds. Ann Arbor, London: Ann Arbor - Humphrey Science Publishers, 1970. 461 pp.

10. Краткий справочник физико-химических величин / ред. К. П. Мищенко, А. А. Равдель. Л.: Химия, 1974. 200 с. [ Handbook of Physicochemical Values / eds. K. P. Mishchenko, A. A. Ravdel'. Leningrad: Khimiya, 1974. 200 pp.]

11. Осипков В. Н. Создание новых пиротехнических источников холодного газа, совершенствование процессов, аппаратов и технологии производства: Автореф. дисс. ... канд. техн. наук: 05.17.08. Бийск, 2004. 20 с. [ Creating new pyrotechnic sources of cold gas, process improvement, equipment and production technology: Ph. D. Thesis (Techn.). Biysk, 2004. 20 pp.]

Поступила в редакцию 21/V/2011;

в окончательном варианте - 03/VIII/2011.

MSC: 80A25

\title{
THERMODYNAMIC CALCULATION OF TEMPERATURE AND COMPOSITION OF THE COMBUSTION PRODUCTS OF PYROTECHNIC AND GAS GENERATING CARTRIDGES FOR PRESSURIZATION POWDER FIRE EXTINGUISHERS
}

\section{O. I. Altuhov ${ }^{1}$, V.V. Frygin ${ }^{2}$}

\author{
1 Samara State Technical University, \\ 244, Molodogvardeyskaya st., Samara, 443100, Russia. \\ 2 Testing Fire-Extinguishing Laboratory of Samara Region, \\ 74, Proletarskaya st., Samara, 443096, Russia. \\ E-mails: oleg.altuhov@bk.ru, wffiere@rambler.ru
}

The main results of thermodynamic calculations of combustion reaction of pyrotechnic gas generating cartridges for powder fire extinguishers are presented in the paper. Adiabatic temperature and combustion products are determined based on the calculations. Chemical compounds for the gas generating cartridge with low temperature generated gases are defined.

Key words: pyrotechnic gas generating cartridges, combustion, temperature, combustion products.

Original article submitted 21/V/2011; revision submitted $03 / \mathrm{VIII} / 2011$.

Oleg I. Altuhov, Junior Researcher, Engineering Center of Self-Propagating High-Temperature Synthesis. Valeriy V. Frygin, Chief of Laboratory. 